\title{
The Correlation between Diabetes, Hypertension\& Kidney Disease with Others Diabetic Induced Disease and Factors among Diabetic Patients in Bangladesh
}

\author{
Sultana-E-Monjerina ${ }^{1 *}$, Farjana Anzin ${ }^{2}$, Tasnim Asiq ${ }^{3}$
}

\author{
${ }^{1}$ Nutrition \& Health Education Officer, BIHS General Hospital, BADAS Basabo Diabetic Center, Dhaka, Bangladesh \\ ${ }^{2}$ Sr. Nutrition Officer, Ibrahim General Hospital \& DCEC, Dhanmondi, NHN, BADAS \& Additional General Secretary of Diabetes Nutrition Society \\ of Bangladesh \\ ${ }^{3}$ Clinical Dietitian Northern Int. Medical College \& Hospital, Dhanmondi Ltd Bangladesh
}

DOI: $10.36347 /$ sjams.2020.v08i08.013

| Received: 11.07.2020 | Accepted: 20.07.2020 | Published: 20.08.2020

*Corresponding author: Sultana-E-Monjerina

Background: The risk of diabetes is related to rising high blood pressure. HBP may be a major risk factor for coronary artery disease, stroke, heart failure, atrial fibrillation, peripheral vascular disease, vision loss, chronic renal disorder and dementia. Hypertension presents as part of metabolic syndrome of insulin resistance in T2DM.HTN is an extremely common co-morbid condition in diabetes, which affects $\sim 20-60 \%$ of patients. In type 1 diabetes, hypertension may replicate the onset of diabetic nephropathy. HTN increases the risk for both macrovascular and microvascular complications, including stroke, coronary artery disease, peripheral vascular disease, retinopathy, nephropathy. HTN is the main risk factor for cardiovascular disease which is the leading cause of death. Hypertension is a major medical and public health issue in our country. Objective: The key objective of the study was to find out the correlation between diabetics, HTN, CKD in association with other diabetics induced diseases and factors among diabetes patients. Materials and Method: It was a cross-sectional descriptive study. The study was conducted in Ibrahim General Hospital \& DCEC, Dhanmondi, NHN, BADAS. The total sample size of the study was 115 . The study period was from October to December 2018. Results: Out of 115 patients, $48.6 \%$ were male and $50.4 \%$ female. In the age group, the highest was $31.5 \%$ of $46-55$ years, followed by $22.8 \%$ of $36-45$ years. According to BMI, $31.3 \%$ were overweight and $1.7 \%$ was underweight. In occupations, housewives $37.3 \%$, followed by service $25.2 \%$. The mean value of FBS was 8.86 \pm 3.62 , AFB 12.78 \pm 4.3 , SBP 129.04 \pm 13.42 , DBP $80.33 \pm 8.15$, TG 204.0, serum creatinine $1.12 \pm 0.344$, LDL $24 \pm 56.83$, HDL 43.15 \pm 18.22 , TT 194 \pm 46.54 , HbA1c 9.58 \pm 2.81 and Hbg 11.57 \pm 1.49 . Calculation: Currently, the diabetics patients of Bangladesh around 8.4 million. HTN, CKD, cancer, respiratory disease, and obesity could increase high if diabetes is poorly controlled.

Keywords: Hypertension, high blood pressure, cardiovascular disease.

Copyright @ 2020: This is an open-access article distributed under the terms of the Creative Commons Attribution license which permits unrestricted use, distribution, and reproduction in any medium for non-commercial use (NonCommercial, or CC-BY-NC) provided the original author and source are credited.

\section{INTRODUCTION}

Diabetes mellitus (DM) commonly known as diabetes, is a faction of metabolic disorders characterized by a high blood sugar level over a prolonged period of time.DM is a state of impaired carbohydrate \& other metabolisms caused by either lack of insulin secretion and or its action. T2DM occurs due to progressive insulin deficiency in the background of insulin resistance [1].The global diabetes prevalence in 2019 is estimated to be $9.3 \%$ (463 million people), rising to $10.2 \%$ (578 million) by 2030 and $10.9 \%$ (700 million) by 2045 . The prevalence is higher in urban $(10.8 \%)$ than rural $(7.2 \%)$ areas and in high-income $(10.4 \%)$ than low-income countries (4.0\%) [2]. Bangladesh is one of the 7 countries of the IDF SEA
(IDF South East Asia region). 463 million people have diabetes in the world and 88 million people in the SEA region by 2045 this will rise to 153 million. Total adult population is $104,015,000$, prevalence of diabetes in adults is $8.1 \%$ \& total cases of diabetes in adults are 8,372,200[3]. Highblood pressure (HBP) is a long-term medical stipulation that causes hypertension. However, long-term HBP may be a major risk factor for coronary artery disease, stroke, heart failure, atrial fibrillation, peripheral vascular disease, vision loss, chronic renal disorder and dementia. Hypertension is called a "silent killer". Most people with hypertension are ignorant of the problem because it may have no warning signs or symptoms. It's a particularly common co-morbid condition in diabetes, distressing $\sim 20-60 \%$ of patients 
with diabetes, depending on obesity, ethnicity, and age[4].The normal $\mathrm{BP}$ is 120 over $80 \mathrm{mmHg}$ but in hypertension, it is higher than 130 over $80 \mathrm{mmHg}$. Unmanaged hypertension can cause a heart attack, stroke and other problems [5]. Hypertension significantly increases the risk of both macro and micro vascular complications including stroke, coronary artery, peripheral vascular, retinopathy, nephropathy and possibly neuropathy diseases. All over the world, hypertension is responsible for $51 \%$ of cerebrovascular disease and $45 \%$ of ischemic heart disease death [6]. Peripheral arterial disease (PAD) also referred to as peripheral vascular disease (PVD), is caused by the narrowing of blood vessels that carry blood to the arms, legs, stomach and kidneys. Other factors associated with cardiovascular diseases, such as C-reactive protein levels and homocysteine levels, also are associated with an increased risk for PAD [7]. Diabetic nephropathy is defined as persistent proteinuria in patients without urinary tract infection or other diseases causing the proteinuria. In patients with type 1 diabetes, the development of clinical nephropathy is a relatively late event; however, in patients with type 2 diabetes, diabetic proteinuria may be present at diagnosis [8]. Reducing the weight by just 3 to 5 percent can help decrease triglycerides and blood sugar and reduce the risk of diabetes. Losing even more weight can help lower blood pressure and blood cholesterol level [9]. The relationship between hypertension and obesity is multifaceted; the etiology is complex and it's not well elucidated [10]. Diet is important in the cause of many chronic diseases. Individual change in dietary behavior has the potential to decrease the burden of chronic disease, particularly cardiovascular disease. Eating a healthy diet can reduce the risk of cardiovascular disease. One should aim to keep saturated fat to 5 or 6 percent of daily calories. And try to keep trans-fat out of diet altogether. Sources of trans-fat include deep fried fast foods, bakery products, packaged snack foods, margarines, crackers, chips and cookies [11]. A Joint WHO/FAO expert consultation on diet, nutrition and the prevention of chronic diseases met in Geneva from 28 January to 1 February 2002. During the past decade, rapid expansion in a number of relevant scientific fields and in particular in the amount of population-based epidemiological evidence has helped to clarify the role of diet in preventing and controlling morbidity and premature mortality resulting from non-communicable diseases (NCDs).The dietary approach to stop hypertension (DASH) diet is a nutritional program assembled in the 1990s and assessed in intervention controlled trials. Its main target was to lower blood pressure and therefore CVD incidence, by nutritional means. The DASH diet comprises vegetables and fruits, as well as low-fat dairy products, whole grains, chicken, fish, and nuts. On the other hand, it is low in fat, meat, sweets, and sodas [12]. Smoking is a major cardiovascular risk factor because of the poisonous effects of the chemicals contained in tobacco. For instance, nicotine causes a rise in blood pressure, narrowing of the blood vessels, irregular heartbeats and spasms of the muscles in arterial walls. Similarly, the carbon monoxide in cigarette smoke damages the inner lining of the blood vessels as well as reduces the oxygen level in blood. This irritates the blood vessel walls and may trigger the onset of atherosclerosis [13]. Sleep deprivation can do more than leave yawning throughout the day, it can harm for health. People who don't get enough sleep have a higher risk of obesity, high blood pressure, heart attack, diabetes and depression. Today's life rhythms and demands are often challenging and require intense physical and psychological efforts in order to be sustained. Physical activity can help to control weight and reduce the chances of developing other conditions that may put a strain on heart, such as high blood pressure, high cholesterol and diabetes [14]. Furthermore, rapid changes in diets and lifestyles that have occurred with industrialization, urbanization, economic development and market globalization have accelerated over the past decade. This is having a significant impact on the health and nutritional status of populations, particularly in developing countries and in countries in transition. While standards of living have improved, food availability has expanded and become more diversified and access to services has increased, there have also been significant negative consequences in terms of inappropriate dietary patterns, decreased physical activities and increased tobacco use and a corresponding increase in diet-related chronic diseases, especially among poor people.

\section{Materials \& Method}

This was a cross-sectional descriptive study. The study was conducted at, National Health Network, Dhanmondi center, Dhaka of Ibrahim General Hospital. The total sample size of the study was 115 diabetes patients both male and female. The study period was from October to December 2018. In this study purposing sampling techniques was followed. Data were collected from both male and female wards of the hospital. After explaining the purpose of the study to the respondent, and obtaining verbal consent and as per selection criteria of the study, data collection was carried out through face to face interviews of the sample populations. The latest blood pressure was recorded from the treatment card results of ECG, RVs, ETT, angiogram, etc. Weight, height, waist, hip, and chest were measured of the participants as per the procedures. Data were checked, and analyzed throughthe software SPSS 23.0 version. Frequency distribution and normal distribution of all continuous variables were checked. Then geometric mean and standard deviation was calculated.

\section{RESUltS}

Out of total 115 patients, female was $51.0 \%$ \& male $49.0 \%$. Female were significantly higher than male patient (Shown figure 1) 


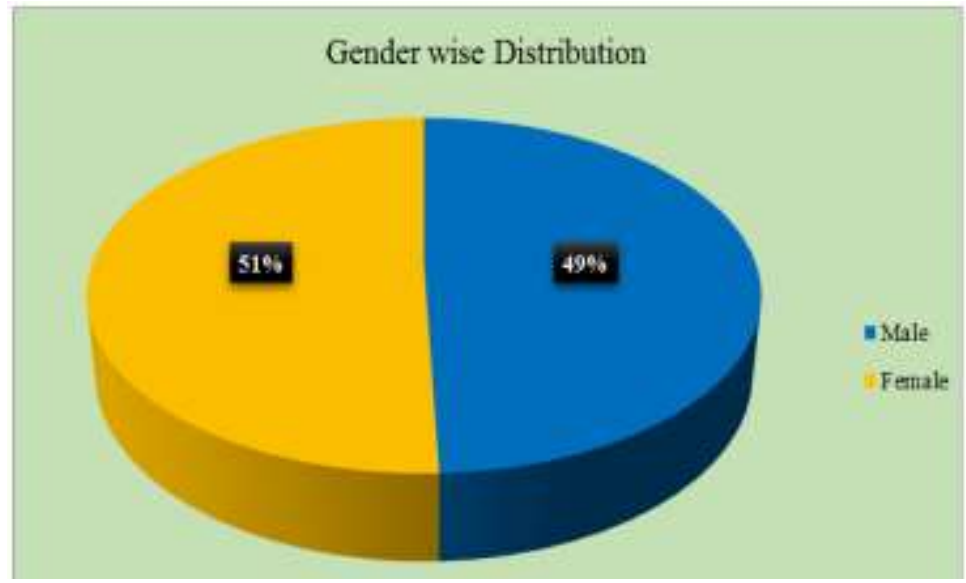

Fig-1: Gender Wise Distribution of the Patients

Out of total 115 patients, highest were $36(31.5 \%)$ of $46-55$ age group, followed by $26(22.8 \%)$ of $36-45$ age group. (Shown in table 2)

Table-2: Distribution of age group among the patients

\begin{tabular}{|l|c|c|}
\hline Patients Age group & Frequency $(\mathbf{n})$ & Percentage $\mathbf{( \% )}$ \\
\hline 15-25 years & 2 & 1.9 \\
\hline 26-35 years & 13 & 10.7 \\
\hline 36-45 years & 26 & 22.8 \\
\hline 46-55 years & 36 & 31.5 \\
\hline 56-65 years & 22 & 18.6 \\
\hline 66-75 years & 11 & 9.9 \\
\hline 75+ years & 5 & 4.6 \\
\hline Base & 115 & 100.0 \\
\hline
\end{tabular}

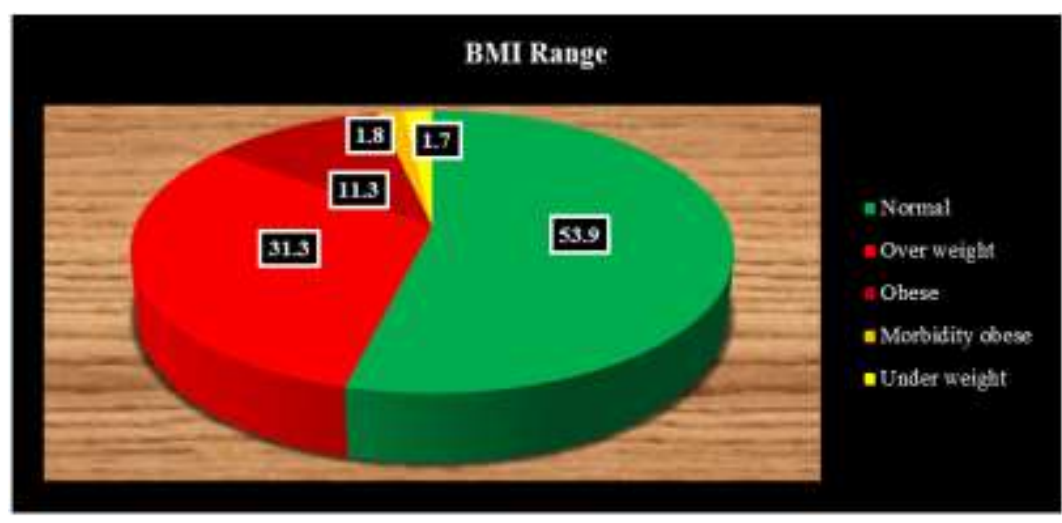

Fig-2: Distribution of Patients by BMI

Regarding occupation of the patients, housewives were highest $43(37.3 \%)$ followed by service $29(25.2 \%)$ (Shown in table 3).

Table-3: Distribution of the patients by their occupation

\begin{tabular}{|l|c|c|}
\hline Occupation & Frequency(n) & Percentage (\%) \\
\hline Service & 29 & 25.2 \\
\hline Business & 24 & 20.8 \\
\hline Skilled Labor & 7 & 6.1 \\
\hline Housewife & 43 & 37.3 \\
\hline Retired & 7 & 6.2 \\
\hline Others & 4 & 3.5 \\
\hline Unemployed & 1 & 0.9 \\
\hline Base & 115 & 100.0 \\
\hline
\end{tabular}




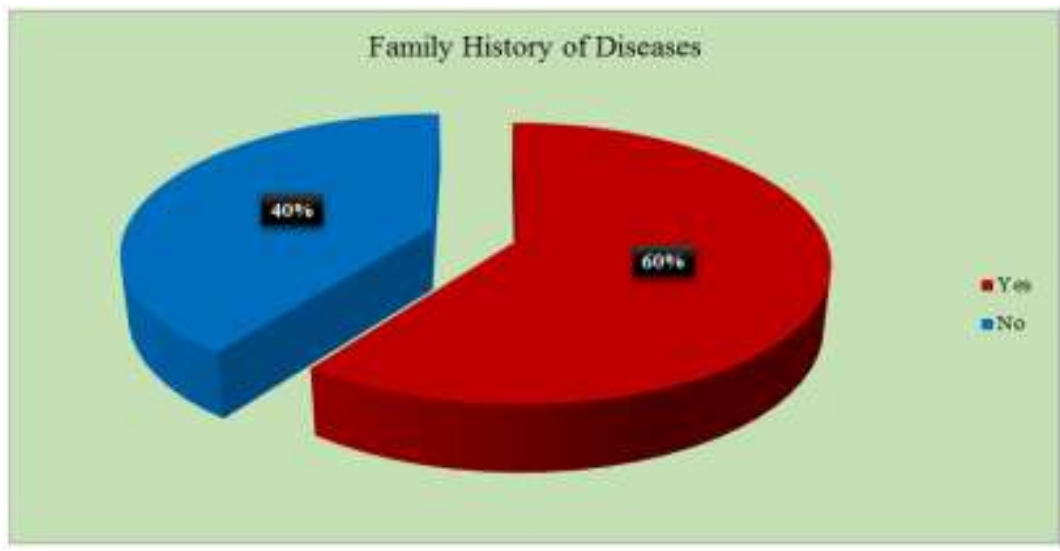

Fig-3: Family History of Diseases

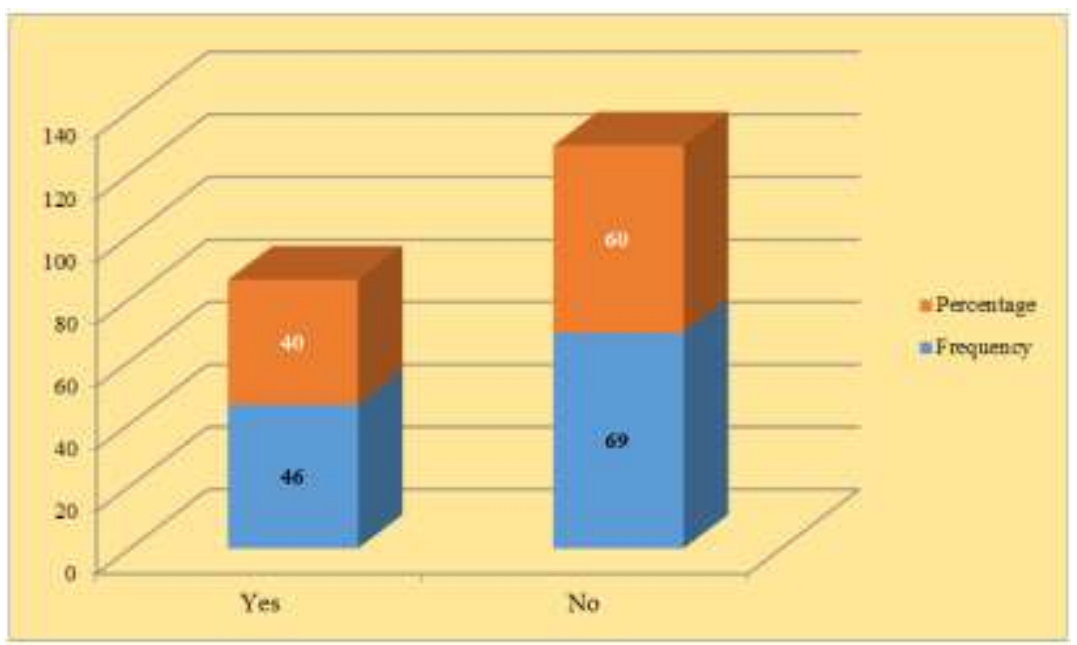

Fig-4: Family Habits of Fast Food Intake

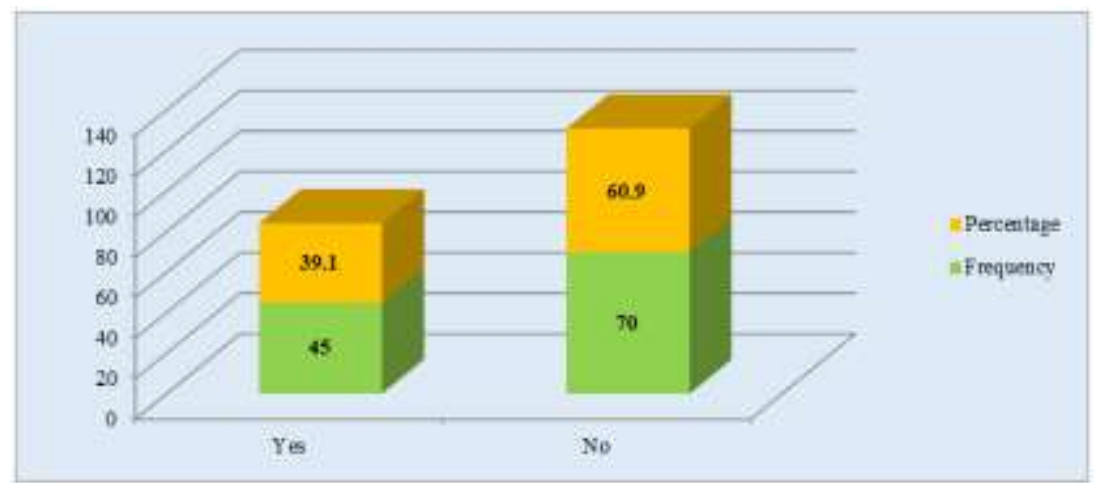

Fig-5: Family Habits of Extra Salt Intake

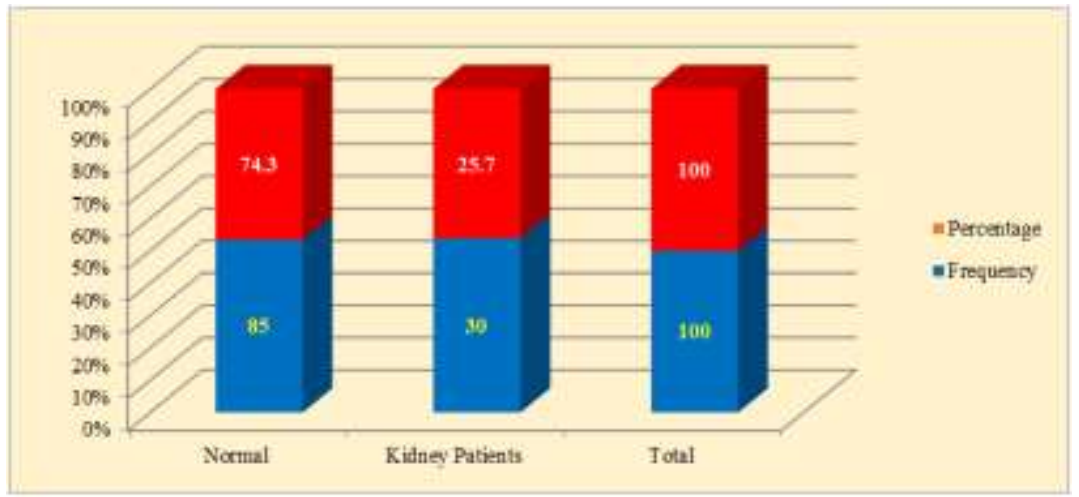

Fig-6: Distribution of Serum Creatinine Level 
Regarding patients biochemical test parameters, the maximum \& minimum mean values were, among 115 patients FBS level test $8.86 \pm 3.62 \mathrm{mmol} / \mathrm{L}, \quad \mathrm{ABF}$ of 112 patients $12.78 \pm 4.38 \mathrm{mmol} / \mathrm{L}$. systolic blood pressure test of 105 patients $129.0 \pm 13.42 \mathrm{~mm} \mathrm{Hg}$, diastolic blood pressure test of 105 patients $80.33 \pm 8.15 \mathrm{mmHg}$, TG level test of 103 patients $204.93 \pm 138.38 \mathrm{mg} / \mathrm{dl}$, serum creatinine of
101 patients $1.12 \pm 0.34412 \mathrm{mg} / \mathrm{dl}$, LDL level of 91 patients $124.93 \pm 56.83 \mathrm{mg} / \mathrm{dl}$, HDLlevel of 95 patients $43.15 \pm 18.22 \mathrm{mg} / \mathrm{dl}$, total cholesterol level of 101 patients $194.46 \pm 46.54 \mathrm{mg} / \mathrm{dl}$, HbAlc of 75 patients $9.58 \pm 2.81$ finally hemoglobin level of 56 patients $11.57 \pm 1.49 \mathrm{gm} / \mathrm{dl}$.

(Shown in table 4).

Table-4: Biochemical testparameters of patients $(\mathrm{N}=115)$

\begin{tabular}{|l|c|c|c|r|}
\hline Biochemical parameters & n & Minimum & Maximum & \multicolumn{1}{c|}{ Mean $($ SD \pm ) } \\
\hline Fasting blood sugar & 115 & 4.40 & 19.10 & $8.86 \pm 3.62$ \\
\hline ABF blood sugar & 112 & 5.10 & 27.20 & $12.78 \pm 4.38$ \\
\hline Systolic BP & 105 & 100.00 & 180.00 & $129.04 \pm 13.42$ \\
\hline Diastolic BP & 105 & 60.00 & 100.00 & $80.33 \pm 8.15$ \\
\hline TG & 103 & 53.00 & 829.00 & $204.93 \pm 138.38$ \\
\hline S. Creatinine & 101 & 0.61 & 3.40 & $1.12 \pm 0.34$ \\
\hline LDL & 91 & 40.00 & 534.00 & $124.93 \pm 56.83$ \\
\hline HDL & 95 & 15.00 & 181.00 & $43.15 \pm 18.22$ \\
\hline T. Cholesterol & 101 & 105.00 & 327.00 & $194.46 \pm 46.54$ \\
\hline HbA1c & 75 & 5.40 & 22.80 & $9.58 \pm 2.81$ \\
\hline Hb & 56 & 7.50 & 15.20 & $11.57 \pm 1.49$ \\
\hline
\end{tabular}

\section{DISCUSSION}

The increasing prevalence of DM worldwide has led to a situation where approximately 360 million people had DM in 2011, ofwhich more than $95 \%$ would have had T2DM. This number is estimated to increase to 366 million by 2030 and it is thought that about half of those will be unaware of their diagnosis $[15,16]$. Undiagnosed T2DM and other disorders of glucose metabolism are risk factors forNCDs. Women with newly diagnosed T2DM have a higher relative risk for CVD mortality than their male counterparts. Physical activity is important in the prevention of the development of T2DM in people with IGT and for the control of glycaemia and related CVD complications. In this study, according to our over 45 to 74 years' age group are most tend to get NCDs because this group is belonging to the late young and old age stage where the physical activity, dietary habit, and social participation get lower eventually. The younger age group is less likely to have CVD because their physical activity is very high. BMI range according to height and weight doesn't highly distress the patients but it has the regular distribution on them. Occupation among the patients shows various results as we found $37.3 \%$ of the total samples are housewives who get T2DM and supposed to get the following complications. Extra salt intake among the patients shows a great significance with their disease. Here found $23.4 \%$ of patients have high blood pressure and all of them having T2DM. The p-value of this cross table is 0.011 which is highly significant. The high lipid range in the blood has a great effect on different types of CVD. A high range of TG has a significant effect on CVD as it takes part in plaque formation inside the artery. Low-density lipoprotein or LDL has the same action on CVD creation in the bloodstream which is named atherosclerosis. As HDL is considered as good cholesterol the higher the HDL level the lower the CVD risk has found among the patients. One particular important issue to think about is people's awareness about salt content in their foods. For instance, in developed countries, researchers reported that a lot of people didn't recognize the "hidden" presence of salt in processed foods. On the other hand, our respondents were aware that salt is added in many foods even if they do not taste salty. According to the recent Bangladesh national survey, $19.4 \%$ of males and $31.9 \%$ of females over 35 years of age are hypertensive and this trend is expected to grow [16].

\section{Conclusion}

Diabetes complications are strongly related to raise high blood pressure (HBP). Long-term HBP may be a major risk factor for coronary artery disease, stroke, heart failure, atrial fibrillation, peripheral vascular disease, vision loss, chronic renal disorder and dementia. Perfect glycemic control is, of fasting blood sugar less than $126 \mathrm{mg} / \mathrm{dL}, 1-\mathrm{h}$ postprandial blood glucose less than $200 \mathrm{mg} / \mathrm{dL}$ and HbA1c 7-6 in patients with type 1 diabetes and 7-8 in patients with type 2 diabetes. In this study mean value of after breakfast blood sugar is $12.78 \mathrm{mmol} / \mathrm{L}$ which is more than the normal range. Diabetes mellitus is characterized by chronic hyperglycemia due to derangement in carbohydrate, fat and protein metabolism. Diabetes mellitus is associated with absolute or relative deficiencies in insulin secretion, insulin action or both. ${ }^{\mathbf{1 7}}$ Diabetic nephropathy affects $30 \%$ of all diabeties and it is a leading cause of end stage renal disease. Assessment of a patient's renal function may be used for two different purposes. One is to diagnose impaired renal function and the other is to detect the presence of a progressive loss of renal function. Diabetes 
nephropathy is charactertised by macro albuminuria more than $300 \mathrm{mg}$ (proteins specifically albumin) in a 24-hour urine collection or macro albuminuria and abnormal renal function as represented by an abnormality in serum creatinine and serum urea. Clinically, diabetes nephropathy is evidenced by proteinuria, decline in glomerular function rate (GFR), and hypertension and has high risk of cardiovascular morbidity and mortality [18]. In diabetes nephropathy, bio-markers viz. serum urea and creatinine are known to be raised with hyperglycemia in uncontrolled diabetes and usually correlate with severity of kidney damage. Measurement of serum urea and creatinine are easily available tests for this purpose which can assist in detection and prevention diabetes kidney disease (DKD) at an early stage and can limit the progression to end stage renal disease (ESRD) $[18,19]$. Creatinine is the breakdown product of creatinine phosphate is released from skeletal muscle at a steady rate. Serum creatinine correlates quite well with the percent of the body that is skeletal muscle. It is filtered by the glomerulus and a small amount is also secreted into the glomerular filtrate by the proximal tubule (hence at low GFR's, the usual reciprocal relationship breaks down and creatinine tends to underestimate how low the GFR has gotten) [20, 21]. Patients with early onset diabetes mellitus have higher GFR levels thus making them a suitable population for study of progressive loss of renal function [22]. In the socio-demographic part of the study, it was found that residential \& educational status, occupation and family income were significantly associated with these diseases. Among the behavioral risk factors, smoking habits, food choice, dietary habit of the respondent, physical activity and family history all were highly significantly associated with NCDs. Hypertension \& CKD along with other diabetes induced disease like retinopathy, neuropathy, CVD, cancer, respiratory disease and obesity could increase high if diabetes is poorly controlled.

\section{REFERENCES}

1. Naish, Jeannette, Court, Denise Syndercombe. From the original on 26 December. 2016; 562.

2. https://www.diabetesresearchclinicalpractice.com/a rticle/S0168-8227(19)31230-6/fulltext 20

3 . https://idf.org/our-network/regions-members/southeast-asia/members/93-bangladesh.html

4. Seftel AD, Sun P, Swindle R. The prevalence of hypertension, hyperlipidemia, diabetes mellitus and depression in men with erectile dysfunction. The Journal of urology. 2004 Jun 1;171(6):2341-5.

5. MacGill M. everything you need to know about hypertension. Medical News Today. 2018.

6. https://books.google.com.bd/books,58.8 million deaths worldwide in the year. 2004.

7. Harris, Russell, and Linda Leininger. "Preventive care in rural primary care practice." Cancer 72. S3; 1993: 1113-1118.
8. Candrilli SD, Davis KL, Kan HJ, Lucero MA, Rousculp MD. Prevalence and the associated burden of illness of symptoms of diabetic peripheral neuropathy and diabetic retinopathy. Journal of Diabetes and its Complications. 2007 Sep 1;21(5):306-14.

9. Jackson R, Lynch J, Harper S. Preventing coronary heart disease. BMJ. 2006; 332: 617-618.

10. Kurukulasuriya LR, Stas S, Lastra G, Manrique C, Sowers JR. Hypertension in obesity. Endocrinology and metabolism clinics of North America. 2008 Sep 1; 37(3):647-62.

11. Arnolda LF. Guidelines for the management of absolute cardiovascular disease risk. 2012.

12. Millen BE, Abrams S, Adams-Campbell L, Anderson CA, Brenna JT, Campbell WW, Clinton $\mathrm{S}$, $\mathrm{Hu} \mathrm{F}$, Nelson $\mathrm{M}$, Neuhouser ML, PerezEscamilla R. The 2015 dietary guidelines advisory committee scientific report: development and major conclusions. Advances in nutrition. 2016 May; 7(3):438-44

13. Sobngwi E, Mbanya JN, Unwin NC, Kengne AP, Fezeu L, Minkoulou EM, Aspray TJ, Alberti KG. Physical activity and its relationship with obesity, hypertension and diabetes in urban and rural Cameroon. International journal of obesity. 2002 Jul;26(7):1009-16.

14. HEARTORG/Conditions/More/Diabetes/AboutDia betes/Pre-diabetes-Modifiable-RiskFactors_UCM_461523_Article.jsp\#1

15. National Vascular Disease Prevention Alliance. Guidelines for the management of absolute cardiovascular disease risk. Melbourne: National Stroke Foundation. 2012.

16. American Diabetes Association. Hypertension management in adults with diabetes. Diabetes care. 2004 Jan 1;27(suppl 1):s65-7.

17. Rao MV, Qiu Y, Wang C, Bakris G. Hypertension and CKD: Kidney Early Evaluation Program (KEEP) and National Health and Nutrition Examination Survey (NHANES), 1999-2004. American Journal of Kidney Diseases. 2008 Apr 1;51(4):S30-7.

18. Shlomo M, Polonsky KS, Larsen PR, Kronenberg HM. Diabetes Mellitus. Willams textbook of endocrinology, 12th Ed. Philadelphia: Elsevier/Saunders. 2011:1371-1435.

19. Schrier RW, Gottschalk CW, Disease of the Kidney, (5th Ed.). Boston, little, Brown. 1993; 2153-89.

20. Anjaneyulu M. Chopra K. Quercetin, an antioxidant bioflavonoid, attenuates diabetic nephropathy in rats. Clinical \& Experimental Pharmacology \& Physiology. 2004; 31:244-8.

21. Rossing K, Christensen PK, Hovind P, Tarnow L, Rossing P, Parving HH. Progression of nephropathy in type 2 diabetic patients. Kidney international. 2004 Oct 1;66(4):1596-605. 